\title{
Services Trade and Labor-Demand Elasticities of Service Sector: Empirical Evidence from China
}

\author{
Hao Wei, Qiang Fu, Sui Yang \\ School of Economics and Business Administration, Beijing Normal University, Beijing, China. \\ Email: weihao1006@gmail.com
}

Received May 26 ${ }^{\text {th }}$, 2012; revised June 25 $5^{\text {th }}$ 2012; accepted July 23 ${ }^{\text {rd }}, 2012$

\begin{abstract}
This paper analyses the impact of services trade on the labor-demand elasticities of service sector with the data of China from 1982 to 2009. We find that: 1) First, no matter in the long run or in the short term, China's services export distinctly impacts on the labor-demand elasticities of service sector. In the long-term influence, the substitution effect is much more powerful than the output effect, however, as to the short period, the output effect is a little stronger than the substitution effect; 2) Second, in the long run, we cannot reject the hypothesis of no relationship between service import openness and the labor-demand elasticities of service sector. Whereas, studying the result of the short term, trade liberalization of services import does affect the service sector labor-demand elasticity weakly.
\end{abstract}

Keywords: Trade Liberalization; Labor-Demand Elasticities; Service Sector; Substitution Effect; Output Effect

\section{Introduction}

From the Reform and Open, China's service sector has been developing quickly and the growth of services trade accelerate rapidly. With the increase of proportion in the China's foreign trade, services trade's average growth rate is higher than that of goods trade, however, from the 1990s the deficit emerges in the service trade. Considering the elastic labor-demand of service sector, various forms of service trade, huge employment supply of service business and the inevitable tendency of liberalization, boosting the service trade is an effective way to promote employment. Through exporting of labor service and undertaking foreign contracted projects, service export could offer more jobs; accompanying by the inflow of foreign funds and advanced technology, service import could also create more employment.

At present, different from most studies which focus on service trade's impact on the employment and wage, this paper concentrates itself on the labor-demand elasticities, and by utilizing the data of China's services trade and service sector from 1982 to 2009, the empirical analysis dedicates to revealing the relationship of China's services trade liberalization and the service sector's labor-demand elasticities, which indicates that through labor-demand elasticities services trade is able to influence the employment. Starting from Cobb-Douglas model and other theories, the paper deduces a basic model and further works out optimization ones to estimate the substitution effect and the output effect. In the empirical analysis part, three tests- the tests of stationarity, cointegration analysis and the error correction model tests are carried out. Lastly, the conclusion and some deduction are reached.

\section{Literature Review}

In the study field concerning the trade's impact on labor market, abundant literature once just focused on the influence exerted by trade on employment and wage. Until 1990s, some scholars have started to promote this research from the perspective of labor-demand elasticity.

In the theory research, Hamermesh (1993) [1] summarizes that an industry's equilibrium own-price labor-demand elasticity is determined by its labor share in the total revenue, constant-output elasticity of substitution between labor and all other factors of production, and product-demand elasticity for industry's output market, in which labor-demand elasticity rises along with the increase of factors substitution elasticity and product-demand elasticity. Rodrik (1997) [2] believes that the impact of trade on labor market in developed countries manifests in the following two aspects. Firstly, trade results in an inward shift in the demand curve for lowskilled labor in advanced countries (the effect of trade is small). Secondly, trade and foreign investment flatten the demand curve for labor at home and increases the elasticity of demand for labor. Since developing countries tend to export low-skilled-intensive products, in devel- 
oped countries the demand for unskilled labor decreases and domestic workers could be substituted by foreign workers more easily. The degree of substitution means labor-demand elasticity. Slaughter (2001) [3] establishes the labor-demand elasticity model composed by substitution effect and output effect on the basis of "fundamental law of factor demand” proposed by Hamermesh (1993) [1].

In the empirical research, trade's impact on labor-demand elasticity is not so significant as the theories shown, and due to the difference on sample selection and specific model building, different empirical studies yield different conclusion.

By using the manufacturing industries data of US from 1961 to 1991, Slaughter (2001) [3] estimates the demand elasticity of production-labor and non-production labor and finds that trade or technology could influence wage model weakly, and factor price change and factor-demand elasticity are still largely unexplained, thus the hypothesis that international trade could increase labordemand elasticity just could be proved partly.

By using India's industry-level data (1980-1997) disaggregated by states and across industries, Hasan, Mitra and Ramaswamy (2003) [4] find that labor-demand elasticities are not only higher for Indian states with more flexible labor regulations, they are also impacted to a larger degree by trade reforms.

By using data (1971-1996) for 6 sectors in manufacturing industries in Tunisia, Haoua and Yagoubi (2004) [5] perform empirical test on the effects of trade liberalization on labor-demand elasticities. They find that labor demand elasticity is large for contract workers while for permanent workers labor demand seems to be inelastic. This supports the conclusion that in liberalization periods labor markets have become more flexible, and that employers prefer recruiting contract workers.

Fajnzylber and Maloney (2005) [6] conduct empirical analysis on the trade liberalization's impact on labordemand elasticities concerning to blue- and white-collar workers for Chile (1979-1995), Colombia (1977-1991) and Mexico (1984-1990). They find that periods of greater openness to trade do not coincide with those of higher labor-demand elasticities in both Chile and Colombia; in Mexico, trade liberation would reduce white-collar labor-demand elasticities, but there are only limited effects on blue-collar elasticities. In brief, the results do not strongly support the hypothesis that trade liberalization has a direct impact on own-wage elasticities.

Zhou Shen (2006) [7] estimates the trade's impact on the labor-demand elasticities of China's manufacturing industries by utilizing panel data across 34 industries from 1993 to 2002. He find that the liberalization of China's manufacturing export could increases the labor- demand elasicities in manufacture sector, and the effect of that is significant statistically and big in degree.

From the literature review, we could conclude that the research on the relationship of service trade and service sector's labor-demand elasicities is in shortage. Whereas, with the rapid development of service trade, its impact on the service sector labor market would increase gradually. Maybe not through the direct channel, service trade could exert influence on wage and employment through labor-demand elasiticities. Consequently, this paper concentrates its attention on service trade and service sector labor-demand elasiticities.

\section{Theory and Estimation Framework}

Supposing in China's service sector, only labor and capital are used. To simply the analysis, this paper assumes that the function of service sector to be a CobbDouglas type (C-D model):

$$
Q=A L^{\alpha} K^{1-\alpha}
$$

Where $A$ denotes total factor productivity, $\alpha$ and $1-\alpha$ denotes the coefficient of labor output elasticity and capital output elasticity respectively. $\alpha$ is between 0 and 1. Greenway, Hine and Wright (1999) [8] discovered, in open economy, parameter $A$ is correlated with trade changes and varies with time in the production function as the following manner:

$$
A_{j}=\mathrm{e}^{\delta_{0} T} M_{j}^{\delta_{1}} X_{j}^{\delta_{2}}, \delta_{0}, \delta_{1}, \delta_{2}>0
$$

where $M_{\mathrm{j}}$ denotes the import penetration of industry $j$, $X$ denotes the export penetration of industry $j, T$ is the time tend and $\delta_{0}, \delta_{1}$ and $\delta_{2}$ are parameters. To demonstrate theoretically how changes in trade policy resulting in greater product market competition and larger product market elasticities, and to establish theoretical underpinnings for the empirical work to follow, Haoua and Yagoubi (2004) [5] propose to work with a model of monopolistic competition, where each firm faces its own less than infinitely elastic demand curve and where there is assumed to be no strategic interaction between firms. Thus, any firm $i$ in industry $j$ is assumed to face an inverse demand curve of the type:

$$
P_{i j}=\theta \bar{p}_{j} Q_{i j}^{-1 / \eta}
$$

where $P_{i j}$ denotes own price, $\bar{p}_{j}$ denotes industry average price, $\theta$ is parameter, $\theta$ is a scaling factor, $Q_{i j}$ denotes firm output, and $\eta$ denotes the (constant) price elasticity of demand

The firm is assumed to face given factor prices. Partially differentiating profits with respect to the $L$ th input and Kth input gives us firm's profit maximization conditions just as the following first order conditions: 


$$
\begin{gathered}
\frac{\alpha \theta(\eta-1)}{\eta} \bar{p}_{j} Q_{i j}^{\frac{\eta-1}{\eta}} L_{i j}^{-1}=w_{j} \\
\frac{(1-\alpha) \theta(\eta-1)}{\eta} \bar{P}_{j} Q_{i j}{ }^{\frac{\eta-1}{\eta}} K_{i j}{ }^{-1}=r_{j}
\end{gathered}
$$

where $L_{i j}$ denotes labor input, $K_{i j}$ denotes capital input, $w_{j}$ denotes the price of the $L$ th input, $r_{j}$ denotes the price of the Kth input. By employing Equations (1), (2), (4) and (5), we could get the following equation:

$$
\begin{aligned}
& \frac{\alpha \theta(\eta-1)}{\eta}\left(\frac{1-\alpha}{\alpha}\right)^{\frac{(1-\alpha)(\eta-1)}{\eta}} A_{j}^{\frac{\eta-1}{\eta}} \bar{p}_{j}\left(\frac{w_{j}}{r_{j}}\right)^{\frac{(1-\alpha)(\eta-1)}{\eta}} L_{i j}^{-\frac{1}{\eta}} \\
& =w_{j}
\end{aligned}
$$

In log form, Equation (6) can be rewritten as:

$$
\begin{aligned}
& \ln L_{i j}=\eta \ln \frac{\alpha \theta(\eta-1)}{\eta}\left(\frac{1-\alpha}{\alpha}\right)^{\frac{(1-\alpha)(\eta-1)}{\eta}}+(\eta-1) \ln A_{j} \\
& -[\eta-(1-\alpha)(\eta-1)] \ln \frac{w_{j}}{\bar{p}_{j}}-(1-\alpha)(\eta-1) \ln \left(\frac{r_{j}}{\bar{p}_{j}}\right)
\end{aligned}
$$

Unite Equation (7) with the Equation (2), we get:

$$
\begin{aligned}
\ln L_{i j} & =\eta \ln \frac{\alpha \theta(\eta-1)}{\eta}\left(\frac{1-\alpha}{\alpha}\right)^{\frac{(1-\alpha)(\eta-1)}{\eta}} \\
& +(\eta-1) \delta_{0} T+(\eta-1) \delta_{1} \ln M_{j} \\
& +(\eta-1) \delta_{2} \ln X_{j}-[\eta-(1-\alpha)(\eta-1)] \ln \frac{w_{j}}{\bar{p}_{j}} \\
& -(1-\alpha)(\eta-1) \ln \left(\frac{r_{j}}{\bar{p}_{j}}\right)
\end{aligned}
$$

In this paper's empirical analysis part, the metric equations are based on the Equation (8). And from Equation (8), the own price elasticity of labor input is given by:

$$
\varepsilon_{1}=\frac{\partial \ln L_{i j}}{\partial \ln \frac{w_{j}}{\bar{p}_{j}}}=-[\eta-(1-\alpha)(\eta-1)]
$$

The partial derivative of the absolute value of the own price elasticity of labor input demand with respect to the product demand elasticity is given by:

$$
\frac{d\left|\varepsilon_{1}\right|}{d \eta}=\frac{d|\eta-(1-\alpha)(\eta-1)|}{d \eta}=\alpha>0
$$

Equation (10) shows the higher the product demand elasticity could lead to the increase of the own price elasticity of labor factor. Furthermore, if the completion triggered by the trade liberalization could make the product demand elasticity in domestic service sector in- crease, the own price elasticity of labor factor would also ascend (Zhou Shen, 2006) [7].

\section{Variables Selection and Optimization Models}

In Equitation (8), we make

$$
\phi_{0}=\eta \ln \frac{\alpha \theta(\eta-1)}{\eta}\left(\frac{1-\alpha}{\alpha}\right)^{\frac{(1-\alpha)(\eta-1)}{\eta}}
$$

and here $\phi_{0}$ stands for the intercept, $\phi_{1}=(\eta-1) \delta_{0}, \phi_{2}=(\eta-1) \delta_{1}, \phi_{3}=(\eta-1) \delta_{2}$, $\phi_{4}=-[\eta-(1-\alpha)(\eta-1)], \quad \phi_{5}=-(1-\alpha)(\eta-1), \mu_{j t}$ is the random error, so we get:

$$
\begin{aligned}
\operatorname{lnL}_{\mathrm{jt}} & =\phi_{0}+\phi_{1} T+\phi_{2} \ln M_{j} \\
& +\phi_{3} \ln X_{j}+\phi_{4} \ln \frac{w_{j}}{\bar{p}_{j}}+\phi_{5} \ln \left(\frac{r_{j}}{\bar{p}_{j}}\right)+\mu_{j t}
\end{aligned}
$$

Considering the time tend could arouse to the unsteadiness, we remove the time tend and get the estimating equation:

$$
\begin{aligned}
\ln L_{j t} & =\phi_{0}+\phi_{1} \ln M_{j}+\phi_{2} \ln X_{j} \\
& +\phi_{3} \ln \frac{w_{j}}{\bar{p}_{j}}+\phi_{4} \ln \left(\frac{r_{j}}{\bar{p}_{j}}\right)+\mu_{j t}
\end{aligned}
$$

The equation above is the static model, which means the employment in current period is affected by the export, import, wage and rate of current period. However, in reality, lots of economic phenomena are dynamic. As a result, we take a time-lag into consideration and therefore the employment in current period is affected by the employment of prior period. The following is the dynamic equation.

$$
\begin{aligned}
\ln L_{j t}= & \phi_{0}+\phi_{1} \ln L_{j, t-1}+\phi_{2} \ln M_{j}+\phi_{3} \ln X_{j} \\
& +\phi_{4} \ln \frac{w_{j}}{\bar{p}_{j}}+\phi_{5} \ln \left(\frac{r_{j}}{\bar{p}_{j}}\right)+\mu_{j t}
\end{aligned}
$$

On the basis of Equation (12), including the factor measuring the trade liberalization, we could estimate the labor-demand elasticities with respect to export and import respectively according to the following equations:

$$
\begin{aligned}
\ln L_{j t}= & \phi_{0}+\phi_{1} \ln L_{j, t-1}+\phi_{2} \ln \left(\frac{w_{j}}{\bar{p}_{j}}\right) \\
& +\phi_{3} \ln X_{j}+\phi_{4} \ln X_{\mathrm{j}} \ln \frac{w_{j}}{\overline{P_{j}}}+\mu_{j t} \\
\ln L_{j t}= & C_{0}+C_{1} \ln L_{j, t-1}+C_{2} \ln \left(\frac{w_{j}}{\bar{p}_{j}}\right) \\
& +C_{3} \ln M_{j}+C_{4} \ln M_{\mathrm{j}} \ln \frac{w_{j}}{\bar{p}_{j}}+\mu_{j t}
\end{aligned}
$$


where $L_{i j}$ denotes the labor demand of industry $j$ in time $t, L_{j, t-1}$ denotes the labor demand of industry $j$ in time $t-1$ and represent the time-lag; $\frac{w_{j}}{\bar{p}_{j}}$ denotes the real wage of industry $j$, and could be calculated by the nominal wage against the consumer price index; $\phi_{2}$ or $C_{2}$ stands for the labor-demand elasticities of industry $j$; $\ln X_{j}$, which is reflected the $\log$ form of the export penetration of industry $j$, is the indicator of the export openness; $\ln M_{j}$, which is reflected the log form of the import penetration of industry $j$, is the indicator of the import openness; $\phi_{3}$ shows the export penetration's influence on the demand of labor, and correspondently $C_{3}$ shows the import penetration's influence on the demand of labor; $\phi_{4}$ measures the impact of export openness on the demand of labor, and $C_{4}$ weighs the impact of import openness on the demand of labor similarly, both of which are the focus of the estimation part; $\mu_{j t}$ is the random error. Since the capital price is usually measured by the central bank's benchmark interest rate, which could not mirror the market level, we do not include the rate into the metric equation.

According to the research conducted by Slaughter (2001) [3], the international trade determines the labor-demand elasticities through the substitution effect and the output effect. Therefore, to estimate the impact of the substitution effect or the output effect on the labordemand elasticities, we establish the equations concerned to labor-demand elasticities with respect to the output (15) (17) and labor-demand elasticities with respect to the capital:

$$
\begin{aligned}
\ln L_{j t}= & \phi_{0}+\phi_{1} \ln L_{j, t-1}+\phi_{2} \ln \left(\frac{w_{j}}{\bar{p}_{j}}\right)+\phi_{3} \ln X_{j} \\
& +\phi_{4} \ln X_{\mathrm{j}} \ln \frac{w_{j}}{\bar{p}_{j}}+\phi_{5} \ln Q_{j}+\mu_{j t} \\
\ln L_{j t}= & \phi_{0}+\phi_{1} \ln L_{j, t-1}+\phi_{2} \ln \left(\frac{w_{j}}{\bar{p}_{j}}\right)+\phi_{3} \ln X_{j} \\
& +\phi_{4} \ln X_{\mathrm{j}} \ln \frac{w_{j}}{\bar{p}_{j}}+\phi_{5} \ln K_{j}+\mu_{j t} \\
\ln L_{j t}= & C_{0}+C_{1} \ln L_{j, t-1}+C_{2} \ln \left(\frac{w_{j}}{\bar{p}_{j}}\right)+C_{3} \ln M_{j} \\
+ & C_{4} \ln M_{\mathrm{j}} \ln \frac{w_{j}}{\bar{p}_{j}}+C_{5} \ln Q_{j}+\mu_{j t} \\
\ln L_{j t}= & C_{0}+C_{1} \ln L_{j, t-1}+C_{2} \ln \left(\frac{w_{j}}{\bar{p}_{j}}\right)+C_{3} \ln M_{j} \\
& +C_{4} \ln M_{\mathrm{j}} \ln \frac{w_{j}}{\bar{p}_{j}}+C_{5} \ln K_{j}+\mu_{j t}
\end{aligned}
$$

where the basic variables' meaning is the same with those in Equations (13) and (14); $Q_{j}$ is the real output of industry $j$, which can be got through the industry $j$ 's gross output against GDP index; $K_{j}$ is the real input of fixed assets, which could be figured out according to the results of the industry $j$ 's nominal input of fixed assets against the price index of investment in fixed assets.

\section{Data}

Due to the limited statistical data, the empirical analysis part just adopts the related data of China's services trade and service sector from 1982 to 2009. To get the import penetration and the export penetration, the data of the services trade is assembled from the statistics results from the WTO website concerning to commercial services. And because of the units used there is billion dollars, we employ the average exchange rate of the yuan against dollar and get the value measured by the units of yuan. To simplify the research, we regard the service sector as the tertiary industry. As to the employment number of the service sector, we utilize the statistics of the tertiary industry's employment from the China Statistical Yearbook as substitution. The average wage of the service sector is got from the results of the total wage of tertiary industry divided by the total employment of tertiary industry. However, considering the lack of the statistics of the total wage of tertiary industry, we use the result of the national total wage minus the sum of the total wage of the primary industry and the second industry. Owing to the change of the statistic scope in 2003, to collect the fixed assets investment of service sector, we use the capital investment data from 1982 to 2002 and the urban fixed assets investment data from 2003 to 2009. The consumer price index, GDP index and the price index of investment in fixed assets are assembled from the China Statistical Yearbook. The CPI and the GDP index are based on the year 1978, while the price index of investment in fixed assets is based on the year 1991 and the previous years' indexes are assumed to be 100 .

\section{Empirical Analysis}

\subsection{Tests of Stationarity}

According to the theories of econometrics, if empirical study aims to set up time series' regression models, the tests of stationarity are required to avoid the spurious regression. A test of stationarity that has become popular widely over the past several years is the unit root test. And the usual methods to conduct the unit root test are DF test, ADF test and PP test. This paper adopts the formal one-ADF test, and utilizes Eviews 6.0 to test the steadiness of the level data and the data after the first order difference. The results of the ADF test indicates 
that unit roots exist in all level data, which reveals the original data are unsteady. However, the ADF test for the data after the first order difference shows the null hypothesis that unit root exists could be rejected. As a result, all the variables are qualified with the cointegration of the first order, and therefore live up to the requirement of cointegration analysis.

\subsection{Cointegration Analysis}

The cointegration analysis is the popular method to deal with the nonstationary time series, and could clearly demonstrate the equilibrium relationship in the long run. So we utilize the Engle-Granger cointegration test to judge whether the independent variables are cointegrated with the dependent ones in Equations (13)-(18), and use ADF test to examine the estimated residual series. The test results show that each model's estimated residual series are significant on the level of $1 \%$. Hence, we can assert that those estimated residual series are steady and the dependent variables are in cointegration relationship with the independent variables.

\subsubsection{Service Export's Impact on Labor-Demand Elasticities}

\subsubsection{Export's Gross Estimate}

On the basis of the model (13), we estimate the gross impact of export on labor-demand elasticities. We get the estimated results in Table 1. On the basis of the results above, we could get the equation of cointegration regression:

$$
\begin{aligned}
\ln L_{t}= & 4.390+0.877 \ln L_{t-1}-0.645 \ln \left(\frac{w}{\bar{P}}\right) \\
& +1.135 \ln X-0.234 \ln X \ln \frac{w}{\bar{P}}
\end{aligned}
$$

As the Table 1 shown, without regard to the influence of export, the service sector's labor-demand elasticity is about -0.644. Export's impact on the labor-demand elasticity is remarkable on the significant level of $10 \%$. The every $10 \%$ increase of export penetration rate (in log form)) could result in the $2.33 \%$ increase of labor-demand elasticity (absolute value), whose effect is powerful. The labor demand of precious period has distinctly positive impact on the labor demand in current period, and the degree of the impact is up to 0.877 . The mortal inertia on the service employment demonstrates the necessity of including the time lag. The export penetration also throws conspicuously positive influence on the labor demand, which indicates the increase of the service export could raise the employment of service sector.

\subsubsection{Export's Estimate with the Output Constraint}

Table 2 is the estimate result of service export's impact
Table 1. Export's gross estimate.

\begin{tabular}{ccccc}
\hline Variable & Coefficient & Std. Error & t-Statistic & Prob. \\
\hline $\ln L_{t-1}$ & 0.877423 & 0.026165 & 33.53438 & 0.0000 \\
$\ln \left(\frac{w}{\bar{P}}\right)$ & -0.643742 & 0.365323 & -1.762118 & 0.0919 \\
$\ln X$ & 1.134611 & 0.564561 & 2.009724 & 0.0569 \\
$\ln X \ln \left(\frac{w}{\bar{P}}\right)$ & -0.232559 & 0.121795 & -1.909430 & 0.0693 \\
$\mathrm{R}^{2}$ & 0.996415 & Mean Dependent Var & 9.646432 \\
Adj-R & 0.995763 & S.D. Dependent Var & 0.416269 \\
S.E. & 0.027097 & F-Statistic & 1528.510 \\
D.W. Stat & 2.156893 & Prob(F-statistic) & 0.000000 \\
\hline
\end{tabular}

Table 2. Export's estimate with the output constraint.

\begin{tabular}{crrrr}
\hline Variable & Coefficient & Std. Error & t-Statistic & Prob. \\
\hline $\ln L_{t-1}$ & 0.617146 & 0.112046 & 5.507952 & 0.0000 \\
$\ln \left(\frac{w}{\bar{P}}\right)$ & -0.751735 & 0.335017 & -2.243872 & 0.0357 \\
$\ln X$ & 1.309772 & 0.518210 & 2.527494 & 0.0196 \\
$\ln X \ln \left(\frac{w}{\bar{P}}\right)$ & -0.266921 & 0.111600 & -2.391774 & 0.0262 \\
$\ln Q$ & 0.079660 & 0.033512 & 2.377059 & 0.0270 \\
$\mathrm{R}^{2}$ & 0.997175 & Mean Dependent Var & 9.646432 \\
Adj-R & 0.996502 & S.D. Dependent Var & 0.416269 \\
S.E. & 0.024619 & \multicolumn{2}{c}{ F-Statistic } & 1482.418 \\
D.W. Stat & 2.167449 & Prob(F-statistic) & 0.000000 \\
\hline
\end{tabular}

on service sector's labor-demand elasticities with the output constraint. On the basis of the results above, we could get the equation of cointegration regression:

$$
\begin{aligned}
\ln L_{t}= & 6.653+0.617 \ln L_{t-1}-0.752 \ln \left(\frac{w}{\bar{P}}\right) \\
& +1.310 \ln X-0.267 \ln X \ln \frac{w}{\bar{P}}+0.080 \ln Q
\end{aligned}
$$

As Table 2 shown, with the output constraint, export's impact on the labor-demand elasticity is remarkable on the significant level of $5 \%$. The every $10 \%$ increase of export penetration rate (in log form) could result in the 2.67\% increase of labor-demand elasticity (absolute value), whose effect is powerful. Because when output is restrained the trade could only change the labor-demand elasticities through influencing the constant-output elasticity of substitution between labor and all other factors of production, the measurement results manifest that the export openness could increase the elasticity of factors' 
substitution effectively, and thus raise the labor-demand elasticities of service sector.

\subsubsection{Export's Estimate with the Capital Constraint}

Table $\mathbf{3}$ is the estimate result of service export's impact on service sector's labor-demand elasticities with the capital constraint. On the basis of the results above, we could get the equation of cointegration regression:

$$
\begin{aligned}
\ln L_{t}= & 6.526+0.965 \ln L_{t-1}-1.263 \ln \left(\frac{w}{\bar{P}}\right) \\
& +2.163 \ln X-0.446 \ln X_{\mathrm{j}} \ln \frac{w}{\bar{P}}+0.227 \ln K
\end{aligned}
$$

As Table 3 shown, with the capital constraint, export's impact on the labor-demand elasticity is remarkable on the significant level of $1 \%$. The every $10 \%$ increase of export penetration rate (in log form) could result in the $4.46 \%$ increase of labor-demand elasticity (absolute value), whose effect is powerful. And the real input of capital throws significant effect on labor-demand elasticity. Because when capital is restrained the trade could only change the labor-demand elasticities through influencing the product-demand elasticity, the measurement results manifest the export openness could increase product-demand elasticity effectively and thus raise the labor-demand elasticities of service sector.

The result indicates that the export openness could increase the labor-demand elasticity significantly through the substitution effect and the output effect from 1982 to 2009. The above analysis indicates that from 1982 to 2009 the export openness could increase the labor-demand elasticity significantly through the substitution effect and the output effect. In this period, if Chinese service sector's export penetration (in log form) increases $10 \%$, the trade's substitution effect would make labor-demand elasticity (absolute value) increase 2.67\%

Table 3. Export's estimate with the capital constraint.

\begin{tabular}{ccccr}
\hline Variable & Coefficient & Std. Error & t-Statistic & Prob. \\
\hline $\ln L_{t-1}$ & 0.965397 & 0.034555 & 27.93826 & 0.0000 \\
$\ln \left(\frac{w}{\bar{P}}\right)$ & -1.263034 & 0.357954 & -3.528483 & 0.0020 \\
$\ln X$ & 2.162685 & 0.564901 & 3.828431 & 0.0010 \\
$\ln X \ln \left(\frac{w}{\bar{P}}\right)$ & -0.446228 & 0.120512 & -3.702782 & 0.0013 \\
$\ln K$ & 0.022652 & 0.006908 & 3.279267 & 0.0036 \\
$\mathrm{R}^{2}$ & 0.997629 & Mean Dependent Var & 9.646432 \\
Adj-R ${ }^{2}$ & 0.997064 & S.D. Dependent Var & 0.416269 \\
S.E. & 0.022554 & F-Statistic & 1767.085 \\
D.W. Stat & 1.712048 & Prob(F-statistic) & 0.000000 \\
\hline
\end{tabular}

and trade's output effect would make labor-demand elasticity (absolute value) increase $4.46 \%$. The substitution effect is almost twice stronger than the output effect, and through those two effects, labor-demand elasticity of service sector (absolute value) could increase $7.13 \%$. According to statistic material, the average export penetration rate (in log form) of China's service sector is $6.09 \%$, and on the basis of the results above, export liberation could increase labor-demand elasticities (absolute value) of China's service sector about 4.34\% from 1982 to 2009, which indicates that trade could exert some power on labor-demand elasticities of China's service sector.

\subsubsection{Service Import's Impact on Labor-Demand Elasticities}

\subsubsection{Import's Gross Estimate}

Table 4 is the estimate result of service import's impact on service sector's labor-demand elasticities with the Gross Estimate. On the basis of the results, we could get the equation of cointegration regression:

$$
\begin{aligned}
\ln L_{t}= & 3.071+0.887 \ln L_{t-1}-0.376 \ln \left(\frac{w}{\bar{P}}\right) \\
& +0.552 \ln M-0.106 \ln M \ln \frac{w}{\bar{P}}
\end{aligned}
$$

As the Table 4 shown, whether it is the labor-demand elasticities without regard to the influence of import, the import's impact on the labor-demand, or the import openness' impact on the labor-demand elasticities, all of them are insignificant on the test level of $10 \%$. Consequently, we couldn't reject the hypothesis of no relationship between service import openness and labor-demand elasticities of the service sector. That is to say, the research results are unable to support the assumption that the service import could increase the labor-demand elasticities of the service sector.

Table 4. Import's gross estimate.

\begin{tabular}{ccccc}
\hline Variable & Coefficient & Std. Error & t-Statistic & Prob. \\
\hline $\ln L_{t-1}$ & 0.887144 & 0.026545 & 33.42060 & 0.0000 \\
$\ln \left(\frac{w}{\bar{P}}\right)$ & -0.376144 & 0.245474 & -1.532320 & 0.1397 \\
$\ln M$ & 0.552327 & 0.323774 & 1.705901 & 0.1021 \\
$\ln X \ln \left(\frac{w}{\bar{P}}\right)$ & -0.105530 & 0.068826 & -1.533288 & 0.1395 \\
$\mathrm{R}^{2}$ & 0.996224 & Mean Dependent Var & 9.646432 \\
Adj-R & 0.995537 & S.D. Dependent Var & 0.416269 \\
S.E. & 0.027808 & F-Statistic & 1451.053 \\
D.W. Stat & 2.320243 & Prob(F-statistic) & 0.000000 \\
\hline
\end{tabular}


6.2.2.2. Import's Estimate with the Capital Constraint

Table 5 is the estimate result of service import's impact on service sector's labor-demand elasticities with the Capital Constraint. On the basis of the results, we could get the equation of cointegration regression:

$$
\begin{aligned}
\ln L_{t} & =3.155+0.939 \ln L_{t-1}-4.899 \ln \left(\frac{w}{\bar{P}}\right) \\
& +0.710 \ln M-0.135 \ln M \ln \frac{w}{\bar{P}}+0.012 \ln K
\end{aligned}
$$

As Table 5 shown, with capital constraint, import's impact on the labor-demand elasticity is remarkable on the significant level of $10 \%$. The every $10 \%$ increase of export penetration rate (in $\log$ form) could result in the $1.35 \%$ increase of labor-demand elasticity.

\subsubsection{Import's Estimate with the Output Constraint}

Table 6 is the estimate result of service import's impact on service sector's labor-demand elasticities with the Output Constraint. On the basis of the results, we could get the equation of cointegration regression:

$$
\begin{aligned}
\ln L_{t}= & 4.394+0.677 \ln L_{t-1}-0.356 \ln \left(\frac{w}{\bar{P}}\right) \\
& +0.515 \ln M-0.945 \ln M \ln \frac{w}{\bar{P}}+0.645 \ln Q
\end{aligned}
$$

As Table 6 shown, $\Delta \ln M \ln \left(\frac{w}{\bar{P}}\right)$ does not pass the test on the significant level of $10 \%$, which means that service import could not remarkably increase the labor-demand elasticities of the service sector through substitution effect.

\section{Error Correction Model}

The cointegration analysis could clearly demonstrates the

Table 5. Import's estimate with the capital constraint.

\begin{tabular}{ccccc}
\hline Variable & Coefficient & Std. Error & t-Statistic & Prob. \\
\hline $\ln L_{t-1}$ & 0.939281 & 0.039341 & 23.87545 & 0.0000 \\
$\ln \left(\frac{w}{\bar{P}}\right)$ & -0.488838 & 0.243763 & -2.005382 & 0.0580 \\
$\ln M$ & 0.709941 & 0.322933 & 2.198413 & 0.0393 \\
$\ln X \ln \left(\frac{w}{\bar{P}}\right)$ & -0.134665 & 0.067982 & -1.980885 & 0.0609 \\
$\ln K$ & 0.012284 & 0.007077 & 1.735840 & 0.0972 \\
$\mathrm{R}^{2}$ & 0.996698 & Mean Dependent Var & 9.646432 \\
Adj-R & 0.995912 & S.D. Dependent Var & 0.416269 \\
S.E. & 0.026617 & \multicolumn{2}{c}{ F-Statistic } & 1267.669 \\
D.W. Stat & 2.098845 & Prob(F-statistic) & 0.000000 \\
\hline
\end{tabular}

Table 6. Import's estimate with the output constraint.

\begin{tabular}{ccccc}
\hline Variable & Coefficient & Std. Error & t-Statistic & Prob. \\
\hline $\ln L_{t-1}$ & 0.676903 & 0.119619 & 5.658810 & 0.0000 \\
$\ln \left(\frac{w}{\bar{P}}\right)$ & -0.355815 & 0.234160 & -1.519534 & 0.1435 \\
$\ln M$ & 0.514934 & 0.309192 & 1.665418 & 0.1107 \\
$\ln X \ln \left(\frac{w}{\bar{P}}\right)$ & -0.094756 & 0.065850 & -1.438960 & 0.1649 \\
$\ln Q$ & 0.064576 & 0.035911 & 1.798237 & 0.0865 \\
$\mathrm{R}^{2}$ & 0.996728 & Mean Dependent Var & 9.646432 \\
$\mathrm{Adj}-\mathrm{R}^{2}$ & 0.995949 & S.D. Dependent Var & 0.416269 \\
S.E. & 0.026495 & \multicolumn{2}{c}{ F-Statistic } & 1279.349 \\
D.W. Stat & 2.312158 & Prob(F-statistic) & 0.000000 \\
\hline
\end{tabular}

equilibrium relationship in the long run, however, in short term, variables often diverge the equilibrium state and gradually adjust to the long-run equilibrium. After the empirical analysis of the cointegration relationships, to learn the export trade's impact on the labor-demand elasticities in short period, we establish the error correction model (ECM) in which the error correction term is included. Get the ECM for (13)-(18) as the following:

$$
\begin{aligned}
& \Delta \ln L_{t}=\rho_{0}+\rho_{1} \Delta \ln L_{t-1}+\rho_{2} \Delta \ln \left(\frac{w}{\bar{P}}\right)_{t}+\rho_{3} \Delta \ln X_{t} \\
& +\rho_{4} \Delta \ln X_{t} \ln \ln \left(\frac{w}{\bar{P}}\right)_{t}+\lambda E C_{t-1}+\varepsilon_{t} \\
& \Delta \ln L_{t}=\rho_{0}+\rho_{1} \Delta \ln L_{t-1}+\rho_{2} \Delta \ln \left(\frac{w}{\bar{P}}\right)_{t}+\rho_{3} \Delta \ln M_{t} \\
& +\rho_{4} \Delta \ln M_{t} \ln \ln \left(\frac{w}{\bar{P}}\right)_{t}+\lambda E C_{t-1}+\varepsilon_{t} \\
& \Delta \ln L_{t}=\rho_{0}+\rho_{1} \Delta \ln L_{t-1}+\rho_{2} \Delta \ln \left(\frac{w}{\bar{P}}\right)_{t} \\
& +\rho_{3} \Delta \ln X_{t}+\rho_{4} \Delta \ln X_{t} \ln \ln \left(\frac{w}{\bar{P}}\right)_{t} \\
& +\rho_{5} \Delta \ln Q_{t}+\lambda E C_{t-1}+\varepsilon_{t} \\
& \Delta \ln L_{t}=\rho_{0}+\rho_{1} \Delta \ln L_{t-1}+\rho_{2} \Delta \ln \left(\frac{w}{\bar{P}}\right)_{t} \\
& +\rho_{3} \Delta \ln X_{t}+\rho_{4} \Delta \ln X_{t} \ln \ln \left(\frac{w}{\bar{P}}\right)_{t} \\
& +\rho_{5} \Delta \ln K_{t}+\lambda E C_{t-1}+\varepsilon_{t} \\
& \Delta \ln L_{t}=\rho_{0}+\rho_{1} \Delta \ln L_{t-1}+\rho_{2} \Delta \ln \left(\frac{w}{\bar{P}}\right)_{t} \\
& +\rho_{3} \Delta \ln M_{t}+\rho_{4} \Delta \ln M_{t} \ln \ln \left(\frac{w}{\bar{P}}\right)_{t} \\
& +\rho_{5} \Delta \ln Q_{t}+\lambda E C_{t-1}+\varepsilon_{t}
\end{aligned}
$$




$$
\begin{aligned}
\Delta \ln L_{t} & =\rho_{0}+\rho_{1} \Delta \ln L_{t-1}+\rho_{2} \Delta \ln \left(\frac{w}{\bar{P}}\right)_{t} \\
& +\rho_{3} \Delta \ln M_{t}+\rho_{4} \Delta \ln M_{t} \ln \ln \left(\frac{w}{\bar{P}}\right)_{t} \\
& +\rho_{5} \Delta \ln K_{t}+\lambda E C_{t-1}+\varepsilon_{t}
\end{aligned}
$$

Table 7 is the estimate results of error correction model. We can find that:

In ECM of the export's impact on the labor-demandelasticities, $\Delta \ln X \ln \left(\frac{w}{\bar{P}}\right)$ passes the test on the significant level of $1 \%$, which indicates that in short run service openness could remarkablely increase the service sector's labor-demand elasticities. The every $10 \%$ increase of export penetration rate (in log form) could result in about 3\% increase of labor-demand elasticity (absolute value), whose effect is powerful. Besides, the coefficient of error correction term passes the test on the significant level of $1 \%$ and the rate of adjustment is $1.103 \%$, which reflects the long-term equilibrium could adjust the short-term fluctuation effectively. Compared to the long-term one, in short term the service export's im- pact on the labor-demand elasticities is much stronger. What's more, with the output constraint and the capital constraint, the coefficients of $\Delta \ln X \ln \left(\frac{w}{\bar{P}}\right)$ are both sig nificant on the level of $1 \%$, but the output effect is much stronger than the substitution effect, which is quite different with the conclusion of the long term.

In ECM of the import's impact on the labor-demand elasticities, $\Delta \ln X \ln \left(\frac{w}{\bar{P}}\right)$ passes the test on the significant level of 5\%, indicting the service import has direct influence on the service sector's labor-demand elasticities, which is obviously different from the results of the cointegration analysis. The coefficient of error correction term passes the test on the significant level of $1 \%$ and the rate of adjustment is $1.358 \%$, which reflects the long-term equilibrium could adjust the short-term fluctuation effectively. But in short term, import penetration (in $\log$ form) increase $10 \%$ could just result in about $0.925 \%$ increase of labor-demand elasticity (absolute value), which shows the service import openness's impact on the service sector's labor-demand elasticities is

Table 7. Estimate results of error correction model.

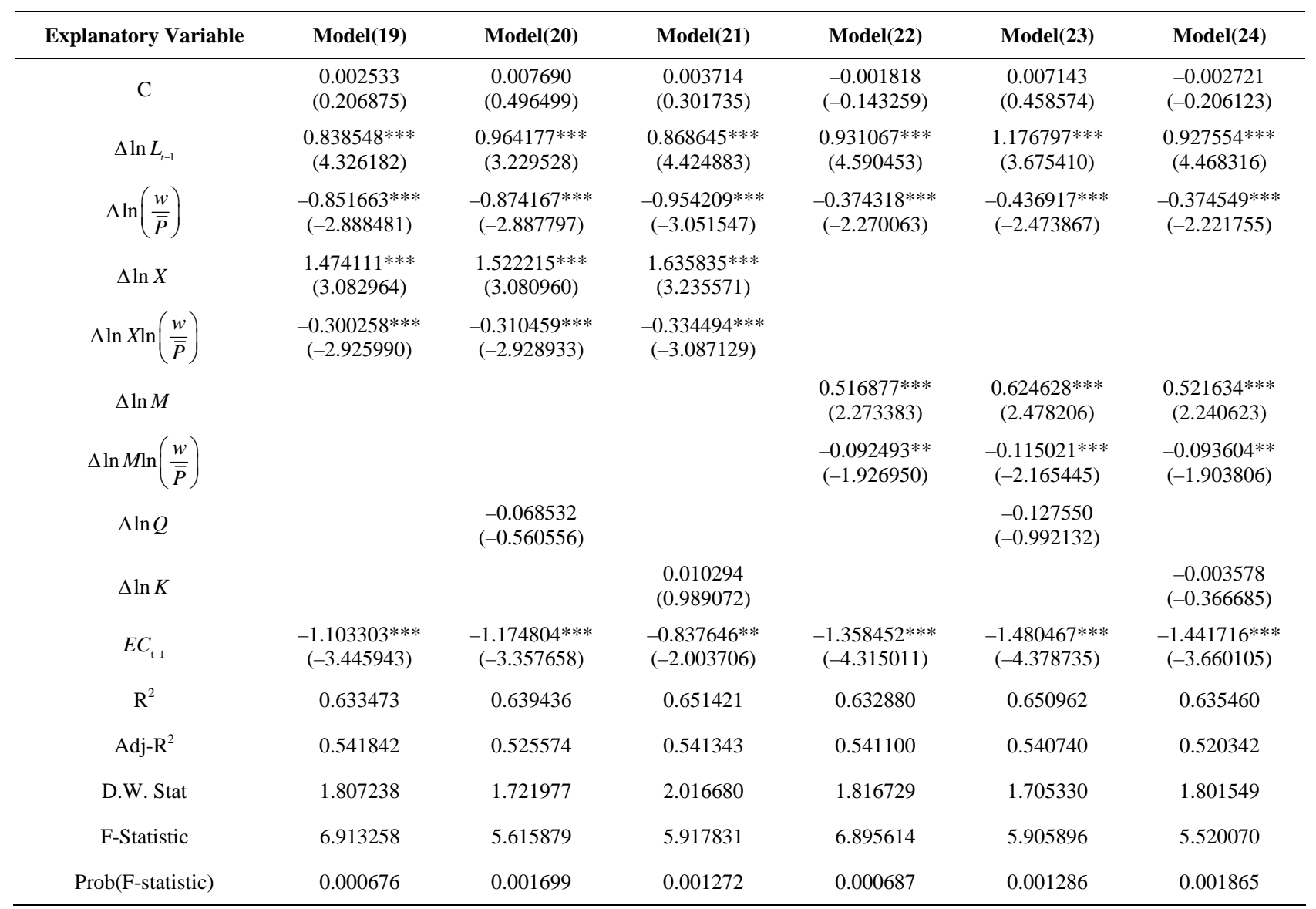

Note: $\Delta$ stands for the first order difference. ${ }^{* * *}, * *, *$ respectively denote that the test passes under the significance level of $1 \%, 5 \%, 10 \%$. 
considerably limited. And different from the export's effect in short term, in the short run the import's substitution effect is much stronger than the output effect.

\section{Conclusions}

This paper analyses the impact of services trade on the labor-demand elasticities of service sector with the data of China from 1982 to 2009. We find that:

1) In long run, China's service export exerts distinctly simulative impact on the service sector labor-demand elasticities, which is significant statistically and big in degree. Export openness could increase the labor-demand elasticity remarkably through the substitution effect and the output effect, but the substitution effect is much stronger than the output effect. In short term, the service export also throws distinctly positive impact on the service sector's labor-demand elasticities, which is more powerful than the influence in the long run, but the output effect is stronger than the substitution effect.

2) In long run, the service import doesn't have direct influence on the service sector's labor-demand elasticities, thus the research results couldn't reject the hypothesis of no relationship between service import openness and labor-demand elasticities of the service sector. In short run, the service import could increase the labor-demand elasticities in some degree. That is to say, as to the short term, trade liberalization of service import does affect the service sector labor-demand elasticity weakly.

The increase of the labor-demand elasticities indicates the status of the labor suppliers is weakened relatively, and meanwhile the shocks brought by the labor demand would arouse the lager fluctuation of wage and employment. Just as the conclusions above shown, no matter in the long run or in the short term, China's services export exerts distinctly stimulative impact on the service sector labor-demand elasticities, therefore even the service export has no direct influence on the wage and employment in service sector, through the labor-demand elasticities service export could exert pressure on the labor market. And as to the service import, in long run its impact on labor-demand elasticities hasn't been proved, but in short run it would aggravate the fluctuation of wage and employment. So China government should pay more attention to the changes of labor-demand elasticities with trade.

\section{Acknowledgements}

This research is supported by "Research Fund of National Social Science" (No.10zd \& 017,No.11AJL005 and No.11FJL008), "The Fundamental Research Funds for the Central University" (No.105563GK), "Scientific Research Fund of Education Ministry of China" (No.10YJC-790272), and "The Fundamental Research Funds for 985 Projects”.

\section{REFERENCES}

[1] D. S. Hamermesh, “Labor Demand,” Princeton University Press, Princeton, 1993.

[2] D. Rodrik, “Has Globalization Gone too Far?” Institute for International Economics, Washington DC, 1997.

[3] M. J. Slaughter, "International Trade and Labor Demand Elasticities,” Journal of International Economics, Vol. 54, No. 1, 2001, pp. 27-56. doi:10.1016/S0022-1996(00)00057-X

[4] R. Hasan, D. Mitra and K. V. Ramaswamy, "Trade Reforms, Labor Regulations and Labor Demand Elasticities: Empirical Evidence From India,” Working Paper 9879, NBER, 2003.

[5] I. Haouas and M. Yagoubi, “Trade Liberalization and Labor-Demand Elasticities: Empirical Evidence from Tunisia,” IZA Discussion Paper, No. 1084, 2004.

[6] P. Fajnzylber and W. F. Maloney, "Labor Demand and Trade Reform in Latin America," Journal of International Economics, Vol. 66, No. 2, 2005, pp. 423-446. doi:10.1016/j.jinteco.2004.08.002

[7] S. Zhou, "Empirical Research on Trade Liberalization's Impact on Industry Sector Labor-Demand Elasticities," World Economy, Vol. 29, No. 2, 2006, pp. 31-40.

[8] D. Greenway, R. C. Hine and P. Wright, "An Empirical Assessment of the Impact of Trade on Employment in the United Kingdom,” European Journal of Political Economy, Vol. 15, No. 3, 1999, pp. 485-500. doi:10.1016/S0176-2680(99)00023-3 